Janna Goryanaya

L.V. Galinskaya, research supervisor

L.V. Galinskaya, language advisor

Welding and Electronics Technical School named after Paton, Dnipropetrovsk

\title{
The Future of Information Technology
}

Computer technology is already a part of our daily life. We have become accustomed to personal computers and smartphones, washing machines and microwave ovens. But what awaits us in the future?

Forthcoming of fully active artificial intelligence is a reality of the nearest future, which will change the world beyond recognition. Future information technology is a quantum computer, endowed with artificial intelligence. Application of quanta will provide an increase in performance by many orders. Amazing properties of quanta allow to use nonformal logic. Quantum computers will be able to solve tasks which are completely inaccessible to modern computing. In addition, according to experts, the data sent through the light channel in any way cannot be intercepted. Thus, the issue of data security will move to an absolutely new level. Global networks, manufacturing processes, traffic and many other aspects of society will be under the control of these supercomputers.

According to the IBM scientists, information technology market is on the verge of an era of cognitive computing systems. "Computer systems of new generation will know how to feel and perceive the world as it is, adapting to environmental conditions, - explained the researchers. - Computers of the new era can mimic human feelings. They learn to see, smell, touch, hear and taste, although they will do that in their own way." "Cognitive computing systems will help us wade through large amounts of information to make better decisions, improve our health, improve living standards and help to overcome any barriers, including long distance, language, and limited physical abilities”, added in IBM.

"Within five years there will be a network of sound sensors that can determine the sound pressure, vibration and frequency of sound waves", the scientists said.

"This capability will allow to predict natural and manmade disasters" - said in IBM. In addition, the computing devices learn to recognize the taste. Scientists are already working on a system that can help in developing new delicious recipes. Ability of computing devices to smell is an innovation that finds application in health care (using subtle smell it can diagnose the dysfunction of certain human organs), agriculture (for healthy plant growth) and public services (monitoring of air pollution and water).

It is difficult to say how exactly the new information world will look, but each of us must be willing to enter it. 